\title{
Characterization of AKT Somatic Mutations in Chinese Breast Cancer Patients
}

This article was published in the following Dove Press journal:

Cancer Management and Research

\author{
Lingzhu Wen ${ }^{1} * *$ \\ Guochun Zhang ${ }^{1, *}$ \\ Chongyang Ren ${ }^{1, *}$ \\ Xuerui $\mathrm{Li}^{1}$ \\ Hsiaopei Mok' \\ Minghan Jia' \\ Yulei Wang' \\ Bo Chen' \\ Kai Li ${ }^{l}$ \\ Li Cao $\mathbb{D}^{\prime}$ \\ Cheukfai Li (1D' \\ Weikai Xiao' \\ Jianguo Lai' \\ Jiali Lin (1D) \\ Guangnan Wei' \\ Yingzi Li (iD) \\ Yuchen Zhang (D' \\ Xiaoqing Chen ${ }^{2}$ \\ Ning Liao' \\ 'Department of Breast Cancer, \\ Guangdong Provincial People's Hospital \\ (Guangdong Academy of Medical \\ Sciences), Guangzhou, Guangdong, \\ People's Republic of China; ${ }^{2}$ Department \\ of Breast Surgical Oncology, Foshan \\ Maternity and Children's Healthcare \\ Hospital Affiliated to Southern Medical \\ University, Foshan, Guangdong, People's \\ Republic of China
}

*These authors contributed equally to this work

Correspondence: Ning Liao Department of Breast Cancer, Guangdong Provincial People's Hospital (Guangdong Academy of Medical

Sciences), No. 106, Zhongshan 2nd Road, Yuexiu District, Guangzhou, Guangdong,

People's Republic of China

$\mathrm{Tel} / \mathrm{Fax}+86$ 20-83827812

Email syliaoning@scut.edu.cn
Purpose: This study aimed to investigate AKT gene mutation status in Chinese breast cancer patients.

Methods: The study included 411 breast cancer patients hospitalized in Guangdong Provincial People's Hospital (GDPH) from June 1, 2017 to September 27, 2018. Mastectomy or breast conserving surgery was performed, and tissue samples were subjected to next-generation sequencing (NGS) to determine AKT gene mutation status. Meanwhile, the expression of human epidermal growth factor receptor 2 (Her2), progesterone receptor (PR), and estrogen receptor (ER) was analyzed by immunohistochemistry staining. The Cancer Genome Atlas (TCGA) database was used for comparative studies.

Results: Patients in the GDPH cohort had an older age $(P<0.001)$, higher postmenopausal rate $(P<0.001)$, larger tumor size $(P<0.001)$, higher histologic type of infiltrating duct cancer $(P<0.001)$, higher metastatic rate $(P<0.001)$, higher expression of ER $(P=$ $0.015)$ and HER2 $(P<0.001)$, and higher percentage of the HR/HER2 subtype $(P<$ $0.001)$ than those in the TCGA cohort. The GDPH cohort displayed lower rates of overall AKT and AKT3 mutation $(P<0.001)$, but a higher AKT1 mutation rate $(P<0.0001)$ compared with the TCGA cohort. Notably, the NGS studies identified missense mutation and copy number amplification as the most common AKT variation type in the GDPH and TCGA cohorts, respectively. Specifically, E17K mutation in AKT1 was predominantly detected in GDPH cohort, while being absent in TCGA cohort. Moreover, in the GDPH cohort, AKT variation was correlated with a number of clinicopathological variables, including age over 50, HER2-, HR+/HER2-, and PR+.

Conclusion: Patients in the GDPH cohort had lower rates of AKT and AKT3 mutation and higher AKT1 mutation rate than those in the TCGA cohort, while harboring missense mutations detected predominantly as E17K mutation in AKT1. In GDPH cohort, there were correlations between AKT mutation and the clinicopathological characteristics of patients.

Keywords: AKT, next-generation sequencing, breast cancer, somatic mutations, population study

\section{Introduction}

Breast cancer has become the most prevalent cancer in women worldwide. ${ }^{1,2}$ For Chinese women, breast cancer is the most commonly diagnosed cancer $(19.2 \%$ of all cases) and the fourth cause of cancer-related deaths (9.1\% of all cancer deaths) in $2018 .^{3}$ As breast cancer patients display diversity in molecular subtypes, pathological features, and therapeutic responses, a comprehensive analysis of new molecular markers and driver gene mutations is crucial for selecting the most appropriate treatment regime for patients. ${ }^{4}$ 
AKT, also known as protein kinase $\mathrm{B}$, a serine/threonine protein kinase, has been shown to control tumor cell migration, metabolism and proliferation, playing an important role in cell survival and cancer progression. There are three AKT genes known as AKT1, AKT2, and AKT3.,6 AKT family proteins are composed of three parts: the pleckstrin homology $(\mathrm{PH})$ domain at the amino terminus, the intermediate catalytic domain and the regulatory domain at the carboxy terminus. AKT is essentially conserved in terms of its carboxy-terminal tail. ${ }^{7}$ AKT variations promote cell motility and induce epithelial mesenchymal transition, resulting in tumorigenesis, metastasis, and poor prognosis of breast cancer. ${ }^{8}$

AKT variation in breast cancer patients has been recently investigated. Studies have showed that AKT variation was detected in $4 \%$ of breast cancer patients and correlated with poor prognosis in patients receiving adjuvant hormone therapy. ${ }^{9,10}$ The Cancer Genome Atlas (TCGA) project is a comprehensive dataset with both cancer genomic and clinical data from cancer patient samples. ${ }^{11,12}$ In the TCGA dataset, only $6 \%$ of samples are Asian breast cancer patients, whereas $69 \%$ are Caucasian cases. ${ }^{13}$ Studies of AKT variations in Chinese breast cancer patients are still lacking. AKT may be a reasonable target for cancer treatment, because the AKT signaling pathway is often dysregulated in up to $70 \%$ of human breast cancers. ${ }^{14}$ AKT is related to and regulated by the metastatic cascade of breast cancer, so it is very important to develop targeted therapy for breast cancer AKT. ${ }^{15}$

Although AKT inhibitors have not yet been used in clinic, a large number of compounds have been demonstrated to inhibit AKT in both in vitro and in vivo models in preclinical studies. Screening the most effective AKT inhibitors for cancer treatment depends on identification of cancer-related mutations in the AKT gene. Thus, more efforts should be made to explore the efficacy and safety of AKT inhibitors.

In this study, we employed next-generation sequencing (NGS) technology to detect AKT variation status in a total of 411 Chinese breast cancer patients. TCGA data were collected for comparison. This study may contribute to a better understanding of AKT variation in clinical settings and facilitate AKT-targeted treatment selection for Chinese breast cancer patients.

\section{Materials and Methods}

\section{Patients and Tumor Specimens}

This study included 411 Chinese primary breast cancer patients who underwent mastectomy or breast conserving surgery in Guangdong Provincial People's Hospital (GDPH) from June 1, 2017 to September 27, 2018. This study was performed in accordance with the Declaration of Helsinki and all patients have signed written informed consents approved by the ethics committee of GDPH before surgery. Clinicopathological characteristics and clinical data for each patient were collected. Tumor tissue samples were obtained from the surgical resection specimens. After being quickly frozen in liquid nitrogen, tissue specimens were kept at $-80{ }^{\circ} \mathrm{C}$ until use. NGS analysis was performed on all tumor specimens.

Both AKT somatic mutation data and clinicopathological features for TCGA groups were obtained from the cBioPortal database (available at: www.cbioportal.org). A total of 1098 breast cancer cases were eligible for this study.

\section{Clinicopathological and Clinical Characteristics}

Human epidermal growth factor receptor 2 (HER2), progesterone receptor (PR), and expression of estrogen receptor (ER) for each breast cancer specimen were routinely assessed by immunohistochemistry (IHC) staining conducted at Department of Pathology in GDPH. In the case of ER and PR, specimens were considered positive when at least $10 \%$ of tumor cells showed nuclear staining. For HER2, a case was defined as positive expression when total and seriously film recoloring were detected in more than $10 \%$ of tumor cells, and/or fluorescence in situ hybridization (FISH) displayed HER2 signals. ${ }^{16}$

Clinical data include gender, age of onset, menstrual status, axillary lymph node status, primary tumor size, distant metastasis status, histological grading, pathological type, and molecular type. The tumors were staged based on TNM classification.

\section{Mutational Analysis of AKT}

NGS technology, also known as massively parallel sequencing (MPS), is a parallel sequencing technology capable of sequencing billions of DNA base pairs in a single run, which can be used for analysis of specific cancer samples. ${ }^{17}$ For sequence analysis, we employed NGS technology to detect AKT variation status. A commercial panel (OncoScreen Plus) composed of 520 genes was used for target capture, and the indexed samples were sequenced on Nextseq500 (Illumina, Inc., USA), and the average sequencing depth of tissue samples was $1,000 \times$. 
DNA isolation and targeted sequencing were performed in Burning Rock Biotech, a College of American Pathologist (CAP)-accredited/Clinical Laboratory Improvement Amendments (CLIA)-certified commercial clinical laboratory, according to optimized protocols as described previously. ${ }^{18,19}$ Sequence data analysis was performed according to the study of Xie et al. ${ }^{20}$ and the copy number was calculated. Copy number variation is defined as the quantitative and statistically significant difference between the coverage data of the genomic region and the reference control. The limit of detecting copy number variations for copy number deletion and amplified copy number variation were 1.5 and 2.64 , respectively.

\section{Data Statistics}

Data were summarized by percentage and frequency for categorical variables. Comparisons of those categorical factors between cohorts were performed using Fisher's exact or Chi-square test. All statistical tests were twosided, and differences were considered statistically significant at $P<0.05$.

\section{Results}

\section{Clinicopathological Characteristics of Patients in GDPH and TCGA Cohorts}

There were significant differences in the clinicopathological characteristics of breast cancer patients between GDPH and TCGA cohorts, including age of onset $(P<0.001)$, menopausal status $(P<0.001)$, tumor size $(P<0.001)$, histological type $(\mathrm{p}<0.001)$, metastasis status $(P<0.001)$, ER status $(P=0.015)$, HER2 status $(P<0.001)$, and HR/HER2 subtype $(P<0.001)$. The above marked disparities prompted us to investigate the differences in AKT variations among different populations of patients with breast cancer. The clinicopathological features of patients in the two cohorts are summarized in Table 1.

\section{Frequency, Type and Location of AKT (Aberration) Mutations of Patients in the Two Cohorts}

Among 411 patients in the GDPH cohort, 41 (9.98\%) were found to harbor 44 AKT variations, while 17.76\% (195/ 1098) of cases in the TCGA cohort displayed 207 AKT variations $(\mathrm{P}=0.0002)$. As shown in Figure 1, compared with the TCGA cohort, the GDPH cohort had a significantly higher mutation rate in AKT1 $(7.06 \%$ vs
$2.00 \%, \mathrm{P}<0.0001)$, but a significantly lower mutation rate in AKT3 $(2.43 \%$ vs $14.2 \%, \mathrm{P}<0.0001)$.

Next, the NGS studies identified missense mutations and copy number amplification (AMP) as the two most common AKT variation types among patients in the two cohorts, which accounted for approximately two-thirds in all cases with AKT variation. As depicted in Figure 2, the GDPH cohort included 31 cases with missense mutation (70.5\%) detected predominantly in AKT1, 10 cases with copy number amplification (22.7\%), 1 case with deletion mutation (2.3\%), and 2 cases with intron mutation (4.5\%). In the meantime, mutation cases in the TCGA cohort comprised 189 cases with AMP (91.3\%) identified mainly in AKT3, 8 cases with missense mutation (3.9\%), 7 cases with homozygous deletions (HOMDEL) (3.4\%), 1 case with same sense mutation $(0.5 \%)$, and 2 cases with nonsense mutation $(1.0 \%)$.

We further analyzed AKT variation domains in the two cohorts. As summarized in Figure 3, out of all 31 missense mutations in GDPH cohort, 25 cases were identified as E17K mutation in AKT1. Conversely, E17K-mutation in AKT1 was absent in the TCGA cohort.

\section{Relationship Between AKT Variations and the Clinicopathological Features}

Patients in each of the two cohorts were divided into AKT wild-type group and AKT variation group. As summarized in Table 2, relationships between the clinicopathological variables and AKT variation status in the two cohorts were analyzed respectively. In the GDPH cohort, the frequency of AKT variations in patients at age over $50(10.23 \%)$ was significantly higher than that in those at age $\leq 50(9.79 \%)(P=$ 0.022). A significantly higher rate of AKT variation was detected in HER2-negative patients $(P=0.011)$ or HR+/HER2- patients $(P=0.010)$ compared with the corresponding controls. Notably, no significant correlation between AKT variation and ER expression was observed, whereas there was a positive correlation between AKT variation and PR expression $(P=$ 0.041). Moreover, no significant correlations were found between AKT variation and other clinicopathological variables, such as menopausal status, tumor sizes, histological type, lymph node involvement, and tumor grade. On the contrary, AKT variation was not significantly correlated with the clinicopathological characteristics in cases of TCGA cohort. 
Table I Clinicopathological Features of Breast Cancer Patients in GDPH and TCGA Databases

\begin{tabular}{|c|c|c|c|c|c|}
\hline \multirow[b]{2}{*}{ Items } & \multicolumn{2}{|c|}{ GDPH Cohort } & \multicolumn{2}{|c|}{ TCGA Cohort } & \multirow[b]{2}{*}{$P$ value } \\
\hline & No. & (\%) & No. & (\%) & \\
\hline Age & \multirow{4}{*}{$\begin{array}{l}235 \\
176\end{array}$} & \multirow{4}{*}{$\begin{array}{l}(57.2) \\
(42.8)\end{array}$} & & & \multirow[t]{4}{*}{$<0.001$} \\
\hline$\leq 50$ & & & 331 & $(30.1)$ & \\
\hline$>50$ & & & 765 & $(69.7)$ & \\
\hline NA & & & 2 & $(0.2)$ & \\
\hline Menopausal status & \multirow{4}{*}{$\begin{array}{l}181 \\
230\end{array}$} & \multirow{4}{*}{$\begin{array}{l}(44.0) \\
(56.0)\end{array}$} & & & \multirow[t]{4}{*}{$<0.001$} \\
\hline Yes & & & 705 & $(64.2)$ & \\
\hline No & & & 268 & $(24.4)$ & \\
\hline NA & & & 125 & $(I 1.4)$ & \\
\hline Tumor sizes $(\mathrm{cm})$ & \multirow{6}{*}{$\begin{array}{l}153 \\
214 \\
28 \\
16\end{array}$} & \multirow{6}{*}{$\begin{array}{l}(37.2) \\
(52.1) \\
(6.8) \\
(3.9)\end{array}$} & & & \multirow[t]{6}{*}{$<0.001$} \\
\hline $\mathrm{TI}(\leq 2)$ & & & 183 & $(16.7)$ & \\
\hline $\mathrm{T} 2(2<\mathrm{T} \leq 5)$ & & & 621 & $(56.6)$ & \\
\hline $\mathrm{T} 3$ or larger $(\mathrm{T}>5)$ & & & 249 & $(22.7)$ & \\
\hline $\mathrm{T} 4$ & & & 20 & $(1.8)$ & \\
\hline NA & & & 25 & $(2.3)$ & \\
\hline Histological type & \multirow{5}{*}{$\begin{array}{l}359 \\
13 \\
39\end{array}$} & \multirow{5}{*}{$\begin{array}{l}(87.3) \\
(3.2) \\
(9.5)\end{array}$} & & & \multirow[t]{5}{*}{$<0.001$} \\
\hline IDC & & & 819 & $(74.6)$ & \\
\hline ILC & & & 211 & $(19.2)$ & \\
\hline Other & & & 66 & $(6.0)$ & \\
\hline NA & & & 2 & $(0.2)$ & \\
\hline Lymph node involvement & \multirow{4}{*}{$\begin{array}{l}210 \\
201\end{array}$} & \multirow{4}{*}{$\begin{array}{l}(5 I .1) \\
(48.9)\end{array}$} & & & \multirow[t]{4}{*}{0.354} \\
\hline Positive & & & 576 & $(52.5)$ & \\
\hline Negative & & & 495 & $(45.1)$ & \\
\hline NA & & & 27 & $(2.5)$ & \\
\hline Metastasis status & \multirow{3}{*}{$\begin{array}{l}26 \\
384\end{array}$} & \multirow{3}{*}{$\begin{array}{l}(6.3) \\
(93.4)\end{array}$} & & & \multirow[t]{3}{*}{$<0.001$} \\
\hline Yes & & & 24 & $(2.2)$ & \\
\hline No & & & 1074 & $(97.8)$ & \\
\hline ER status & \multirow{4}{*}{$\begin{array}{l}293 \\
118\end{array}$} & \multirow{4}{*}{$\begin{array}{l}(71.3) \\
(28.7)\end{array}$} & & & 0.015 \\
\hline Positive & & & 809 & (73.7) & \\
\hline Negative & & & 237 & $(21.6)$ & \\
\hline NA & & & 52 & $(4.7)$ & \\
\hline PR status & & & & & 0.707 \\
\hline Positive & 272 & $(66.2)$ & 701 & $(63.8)$ & \\
\hline Negative & 139 & $(33.8)$ & 342 & $(3 I .1)$ & \\
\hline NA & & & 55 & $(5.0)$ & \\
\hline Hormone receptor status & & & & & 0.133 \\
\hline Positive & 309 & $(75.2)$ & 826 & $(75.2)$ & \\
\hline Negative & 102 & $(24.8)$ & 222 & $(20.2)$ & \\
\hline NA & & & 50 & $(4.6)$ & \\
\hline HER2 status & & & & & $<0.001$ \\
\hline Positive & 121 & $(29.4)$ & 196 & $(17.9)$ & \\
\hline Negative & 290 & $(70.6)$ & 760 & $(69.2)$ & \\
\hline NA & & & 142 & $(12.9)$ & \\
\hline
\end{tabular}

(Continued) 
Table I (Continued).

\begin{tabular}{|l|l|l|l|l|l|}
\hline \multirow{2}{*}{ Items } & \multicolumn{2}{|l|}{ GDPH Cohort } & \multicolumn{2}{l|}{ TCGA Cohort } \\
\cline { 2 - 5 } & No. & (\%) & No. & (\%) \\
\hline $\begin{array}{l}\text { Ki67 index } \\
\geq 14 \% \\
<14 \%\end{array}$ & 44 & $(10.7)$ & NA value \\
\hline $\begin{array}{l}\text { HR/HER2 status } \\
\text { HR-/HER2- }\end{array}$ & 367 & $(89.3)$ & NA \\
HR-/HER2+ & 53 & $(12.9)$ & $(11.9)$ & 160 & \\
HR+/HER2- & 49 & $(57.7)$ & 41 & $(14.6)$ \\
HR+/HER2+ & 237 & $(17.5)$ & 599 & $(3.7)$ \\
NA & 72 & 155 & $(54.6)$ \\
\end{tabular}

Abbreviations: GDPH, Guangdong Provincial People's Hospital; TCGA, The Cancer Genome Atlas; NA, not applicable; IDC, invasive ductal carcinoma; ILC, invasive lobular carcinoma; ER, estrogen receptor; PR, progesterone receptor; HER2, human epidermal growth factor receptor 2.

\section{Discussion}

In the current public database, the Asian population, especially the Chinese population, accounts for only a small percentage. ${ }^{13}$ It is necessary to test the generalizability of the TCGA profiles in the Asian population of breast cancer patients. Here, we performed a comparative study between 411 patients with breast cancer in the GDPH cohort and
1098 cases in the TCGA cohort, and found that AKT variation rates in the two groups were $9.98 \%$ and $17.76 \%$, respectively, showing a significant difference between them $(P=0.0002)$.

It has been reported that a subset of human malignancies harbor AKT1 mutations related to overactivation of AKT. ${ }^{21,22}$ Gene mutation is less likely to activate

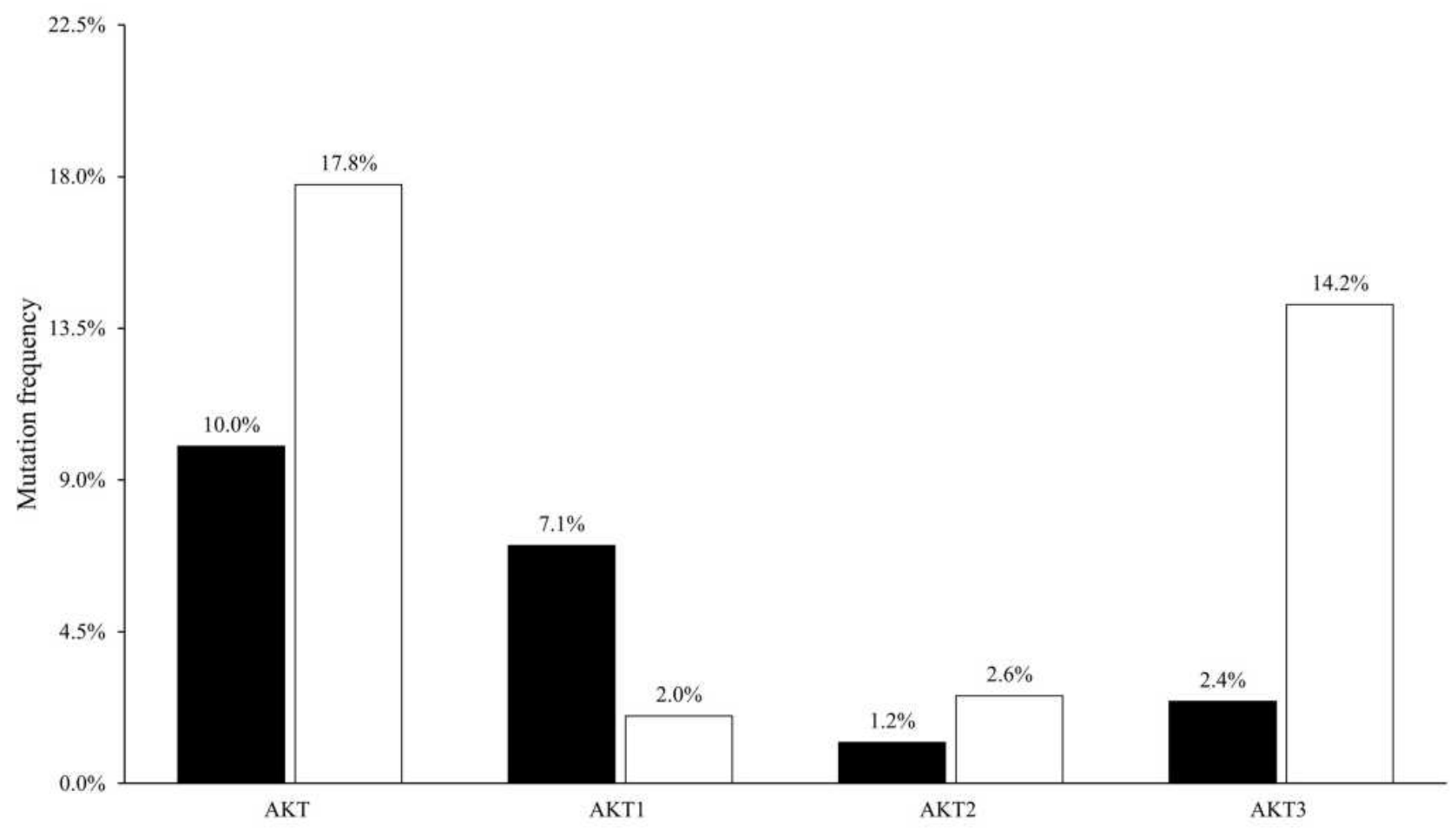

Figure I The mutation rates of AKT, AKTI, AKT2, and AKT3 in GDPH and TCGA cohorts of patients with breast cancer. Abbreviations: GDPH, Guangdong Provincial People's Hospital; TCGA, The Cancer Genome Atlas. 

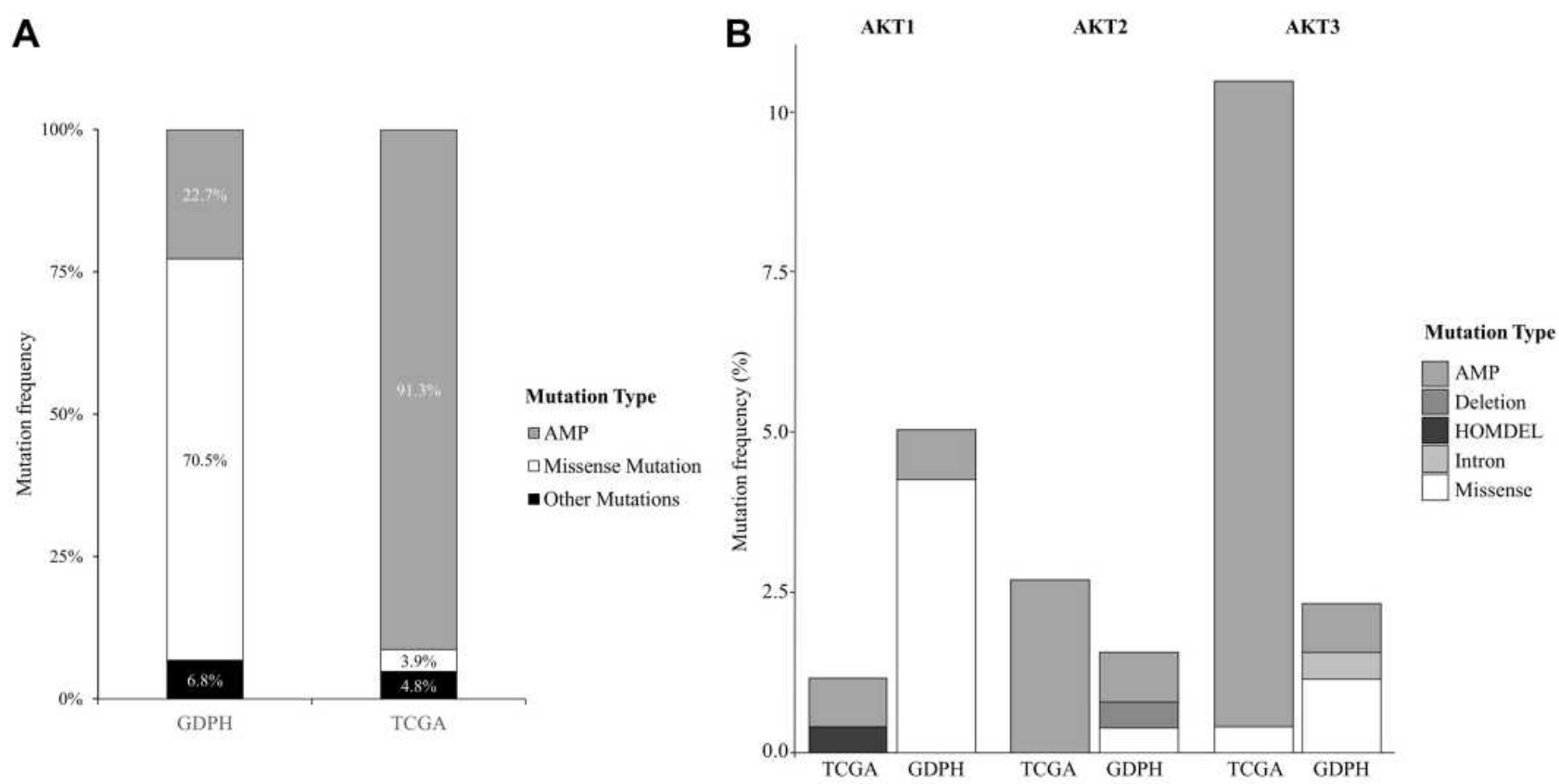

Figure 2 The frequency of different mutation types of (A) AKT, (B) AKTI, AKT2, and AKT3 in the two cohorts.

Abbreviations: GDPH, Guangdong Provincial People's Hospital; TCGA, The Cancer Genome Atlas; AMP, copy number amplification; HOMDEL, homozygous deletions.

AKT in comparison with other activation modes, such as amplification, overexpression, and phosphorylation. Yet, mutations in upstream/downstream AKT regulators may affect the carcinogenicity of $\mathrm{AKT}^{23}$ AKT is considered an attractive target for cancer treatment, and efforts are being made to identify specific inhibitors of AKT with acceptable drug properties. Although AKT inhibitors have been in clinical trials for several years, they have not been specifically evaluated in AKT1mutant tumors. ${ }^{24}$ Identification of the most effective AKT inhibitor for cancer treatment is dependent on cancer-related mutations in the AKT gene. There are a huge number of compounds that can inhibit AKT in both in vitro and in vivo models on preclinical studies. Based on the inhibition mechanisms and chemical scaffolds, AKT inhibitors are mainly classified as ATP-competitive inhibitors, allosteric inhibitors and Irreversible inhibitors. ${ }^{25}$ Commonly used AKT inhibitors in clinical trials are presented in Table $3 .^{5,25}$

Among these AKT inhibitors, AZD5363 is the firstin-human oral evaluation in treating breast cancer. A few phase I clinical trials for AZD5363 alone or in combination with other drugs have been completed. These phase I clinical trials showed well tolerated and accomplished plasma levels as well as vigorous target modulation in breast tumors. ${ }^{26,27}$ These phase I data promoted phase II clinical studies of AZD5363. ${ }^{28,29}$
Besides, there is an ongoing phase III double-blind randomized study assessing the efficacy and safety of Capivasertib (AZD5363) plus Paclitaxel versus placebo plus Paclitaxel as first-line treatment for patients with histologically confirmed, locally advanced (inoperable) or metastatic triple negative breast cancer (TNBC).

The significance of the E17K mutation in breast cancer is still unclear. According to reports, this mutation has dual effects, such as anti-tumor effects (inhibition of cell proliferation and promotion of apoptosis) and carcinogenic effects (promoting cell migration). ${ }^{30}$ Direct or indirect inhibition of E17K function in breast cancer patients is not necessarily an effective treatment strategy. ${ }^{30}$ Therefore, further analysis of the role of E17K mutation in tumorigenesis is needed. An oncogenic activating mutation (E17K) within the PH domain of AKT1 has been identified in a few types of solid tumors. This mutation has been reported in $1.4-8 \%$ of cases with breast cancer. ${ }^{31,32}$ Although this low frequency precludes drawing any authoritative conclusions, a large-scale genotyping study (547 breast tumors and 41 breast cancer cell lines) revealed that AKT1 mutations were solely observed in tumors expressing both ER and PR. ${ }^{32}$ Specifically, it has been shown that AKT1-E17K mutation resulted in membrane binding of AKT and decreased sensitivity to allosteric inhibitors. ${ }^{33}$ In this study, we found that $70.5 \%$ of mutations in the 


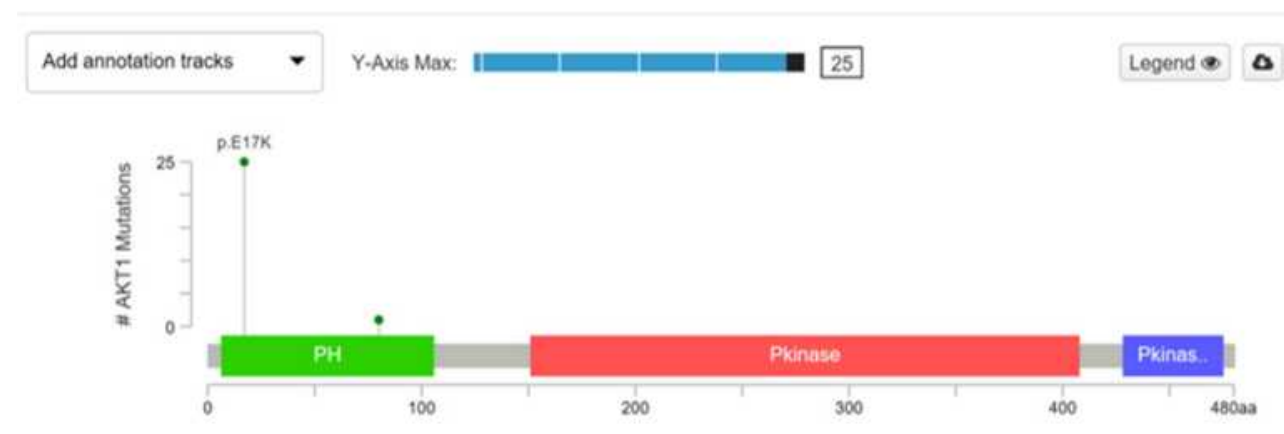

A
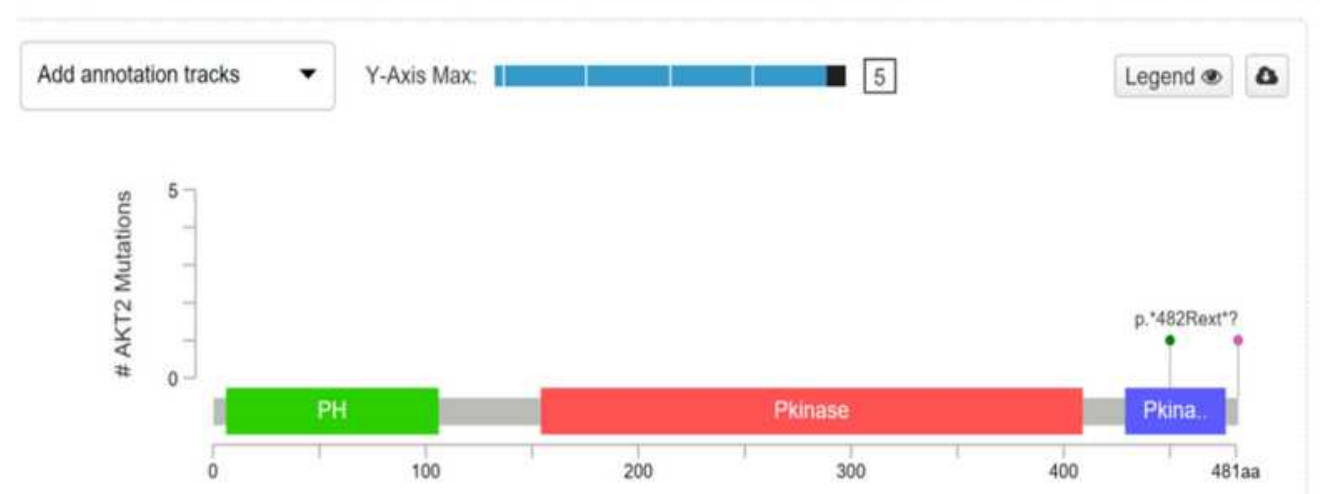

B

$\mathbf{B}$

AKT1

NM_001014431 -

RefSeq: NM_001014431

Ensembl: ENST00000349310

CCDS: CCDS9994

UniProt: AKT1_HUMAN

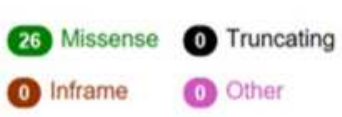

View 3D Structure

AKT2

NM_001626 -

\section{RefSeq: NM_001626}

Ensembl: ENST00000392038

CCDS: CCDS12552

UniProt: AKT2_HUMAN

(1) Missense (0) Truncating
(1) Inframe (1) Other

View 3D Structure

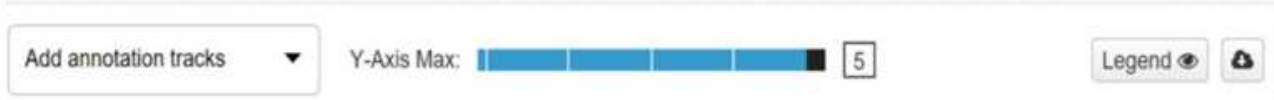

AKT3

NM_005465 -

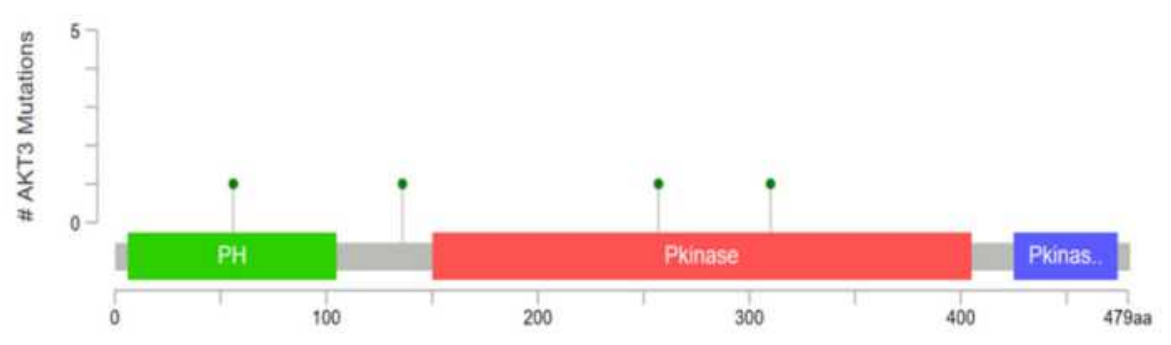

C

RefSeq: NM_005465

Ensembl: ENSTO0000263826

CCDS: CCDS31077

UniProt: AKT3_HUMAN

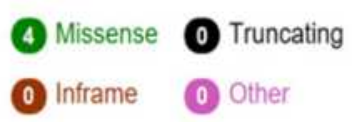

View 3D Structure

Figure 3 Diagram of domains of (A) AKTI, (B) AKT2 and (C) AKT3 with mutations identified in the GDPH cohort. Abbreviation: $\mathrm{PH}$, pleckstrin homology.

Chinese population were missense mutations, among which $80.6 \%$ were detected in the major hotspots concentrated in the helical region (E17K). Conversely, AKT1-E17K mutation was absent in patients of the TCGA cohort. This unique high-frequency mutation in the Chinese population suggests that it could serve as a risk factor for breast cancer in the Asian population. The E17K mutation is located near the specific binding site of PI $(3,4,5) \mathrm{P}_{3}$ in the PH domain of AKT1, and is associated with human breast, colorectal, ovarian, and lung cancer. ${ }^{34,35}$ Previous studies have shown that the E17K mutation may cause significant ${ }^{35}$ changes in the $\mathrm{PH}$ domain of AKT1 and induce resistance to AKT inhibitors. ${ }^{35}$ Therefore, more clinical trials are needed to differentiate antineoplastic effects of different AKT inhibitors prior to being used for different patients. 
Table 2 Correlation Between Clinicopathological Features and AKT Family Mutation in GDPH and TCGA Databases

\begin{tabular}{|c|c|c|c|c|c|c|c|c|c|c|}
\hline & \multicolumn{5}{|c|}{ GDPH Group } & \multicolumn{5}{|c|}{ TCGA Group } \\
\hline & \multicolumn{2}{|c|}{ WT AKT } & \multicolumn{2}{|c|}{ MT AKT } & & \multicolumn{2}{|c|}{ WT AKT } & \multicolumn{2}{|c|}{ MT AKT } & \\
\hline & \multicolumn{2}{|c|}{$n=370$} & \multicolumn{2}{|c|}{$n=41$} & & \multicolumn{2}{|c|}{$n=903$} & \multicolumn{2}{|c|}{$n=195$} & \\
\hline & \multicolumn{2}{|c|}{$n(\%)$} & \multicolumn{2}{|c|}{$n(\%)$} & $\mathbf{P}$ & \multicolumn{2}{|c|}{ n(\%) } & \multicolumn{2}{|c|}{$n(\%)$} & $P$ \\
\hline $\begin{array}{l}\text { Age } \\
\qquad 50 \\
>50 \\
\text { NA }\end{array}$ & $\begin{array}{l}212 \\
158\end{array}$ & $\begin{array}{l}(90.2) \\
(89.8)\end{array}$ & $\begin{array}{l}23 \\
18\end{array}$ & $\begin{array}{l}(9.8) \\
(10.2)\end{array}$ & 0.022 & $\begin{array}{l}263 \\
638 \\
2\end{array}$ & $\begin{array}{l}(79.5) \\
(83.4) \\
(100.0)\end{array}$ & $\begin{array}{l}68 \\
127 \\
0\end{array}$ & $\begin{array}{l}(20.5) \\
(16.6) \\
(0.0)\end{array}$ & 0.117 \\
\hline $\begin{array}{l}\text { Menopausal status } \\
\text { Yes } \\
\text { No } \\
\text { NA }\end{array}$ & $\begin{array}{l}164 \\
206 \\
0\end{array}$ & $\begin{array}{l}(90.6) \\
(89.6) \\
(0.0)\end{array}$ & $\begin{array}{l}17 \\
24 \\
0\end{array}$ & $\begin{array}{l}(9.4) \\
(10.4) \\
(0.0)\end{array}$ & 0.726 & $\begin{array}{l}590 \\
218 \\
95\end{array}$ & $\begin{array}{l}(83.7) \\
(81.3) \\
(76.0)\end{array}$ & $\begin{array}{l}115 \\
50 \\
30\end{array}$ & $\begin{array}{l}(16.3) \\
(18.7) \\
(24.0)\end{array}$ & 0.384 \\
\hline $\begin{array}{l}\text { Tumor sizes }(\mathrm{cm}) \\
\text { TI }(\leq 2) \\
\text { T2 }(2<\mathrm{T} \leq 5) \\
\text { T3 or larger }(\mathrm{T}>5) \\
\text { T4 } \\
\text { NA }\end{array}$ & $\begin{array}{l}132 \\
198 \\
27 \\
13 \\
0\end{array}$ & $\begin{array}{l}(86.3) \\
(92.5) \\
(96.4) \\
(81.3) \\
(0.0)\end{array}$ & $\begin{array}{l}21 \\
16 \\
1 \\
3 \\
0\end{array}$ & $\begin{array}{l}(13.7) \\
(7.5) \\
(3.6) \\
(18.8) \\
(0.0)\end{array}$ & 0.088 & $\begin{array}{l}157 \\
512 \\
197 \\
17 \\
20\end{array}$ & $\begin{array}{l}(85.8) \\
(82.4) \\
(79.1) \\
(85.0) \\
(80.0)\end{array}$ & $\begin{array}{l}26 \\
109 \\
52 \\
3 \\
5\end{array}$ & $\begin{array}{l}(14.2) \\
(17.6) \\
(20.9) \\
(15.0) \\
(20.0)\end{array}$ & 0.338 \\
\hline $\begin{array}{l}\text { Histological type } \\
\text { IDC } \\
\text { ILC } \\
\text { Other } \\
\text { NA }\end{array}$ & $\begin{array}{l}325 \\
12 \\
33 \\
0\end{array}$ & $\begin{array}{l}(88.1) \\
(92.3) \\
(84.6) \\
(0.0)\end{array}$ & $\begin{array}{l}34 \\
1 \\
6 \\
0\end{array}$ & $\begin{array}{l}(9.2) \\
(7.7) \\
(15.4) \\
(0.0)\end{array}$ & 0.485 & $\begin{array}{l}667 \\
175 \\
59 \\
2\end{array}$ & $\begin{array}{l}(81.4) \\
(82.9) \\
(89.4) \\
(100.0)\end{array}$ & $\begin{array}{l}152 \\
36 \\
7 \\
0\end{array}$ & $\begin{array}{l}(18.6) \\
(17.1) \\
(10.6) \\
(0.0)\end{array}$ & 0.255 \\
\hline $\begin{array}{l}\text { Lymph node involvement } \\
\text { Positive } \\
\text { Negative } \\
\text { NA }\end{array}$ & $\begin{array}{l}186 \\
184 \\
0\end{array}$ & $\begin{array}{l}(88.6) \\
(87.2) \\
(0.0)\end{array}$ & $\begin{array}{l}24 \\
17 \\
0\end{array}$ & $\begin{array}{l}(11.4) \\
(8.1) \\
(0.0)\end{array}$ & 0.315 & $\begin{array}{l}408 \\
472 \\
23\end{array}$ & $\begin{array}{l}(70.8) \\
(95.4) \\
(85.2)\end{array}$ & $\begin{array}{l}87 \\
104 \\
4\end{array}$ & $\begin{array}{l}(15 . I) \\
(2 I .0) \\
(14.8)\end{array}$ & 0.838 \\
\hline $\begin{array}{l}\text { Metastasis status } \\
\text { Yes } \\
\text { No } \\
\text { NA }\end{array}$ & $\begin{array}{l}24 \\
345 \\
1\end{array}$ & $\begin{array}{l}(92.3) \\
(89.8) \\
(100.0)\end{array}$ & $\begin{array}{l}2 \\
39 \\
0\end{array}$ & $\begin{array}{l}(7.7) \\
(10.2) \\
(0.0)\end{array}$ & 0.946 & $\begin{array}{l}21 \\
882\end{array}$ & $\begin{array}{l}(87.5) \\
(82.1)\end{array}$ & $\begin{array}{l}3 \\
192\end{array}$ & $\begin{array}{l}(12.5) \\
(17.9)\end{array}$ & 0.495 \\
\hline $\begin{array}{l}\text { Tumor grade } \\
\begin{array}{l}\text { I } \\
2 \\
3 \\
\text { Unknown }\end{array}\end{array}$ & $\begin{array}{l}15 \\
166 \\
181 \\
8\end{array}$ & $\begin{array}{l}(100.0) \\
(87.4) \\
(91.4) \\
(100.0)\end{array}$ & $\begin{array}{l}0 \\
24 \\
17 \\
0\end{array}$ & $\begin{array}{l}(0.0) \\
(12.6) \\
(8.6) \\
(0.0)\end{array}$ & 0.174 & NA & & & & \\
\hline $\begin{array}{l}\text { ER status } \\
\text { Positive } \\
\text { Negative } \\
\text { NA }\end{array}$ & $\begin{array}{l}261 \\
109\end{array}$ & $\begin{array}{l}(89.1) \\
(92.4)\end{array}$ & $\begin{array}{l}32 \\
9\end{array}$ & $\begin{array}{l}(10.9) \\
(7.6)\end{array}$ & 0.313 & $\begin{array}{l}662 \\
199 \\
42\end{array}$ & $\begin{array}{l}(81.8) \\
(84.0) \\
(80.8)\end{array}$ & $\begin{array}{l}147 \\
38 \\
10\end{array}$ & $\begin{array}{l}(18.2) \\
(16.0) \\
(19.2)\end{array}$ & 0.448 \\
\hline $\begin{array}{l}\text { PR status } \\
\text { Positive } \\
\text { Negative } \\
\text { NA }\end{array}$ & $\begin{array}{l}239 \\
131\end{array}$ & $\begin{array}{l}(87.9) \\
(94.2)\end{array}$ & $\begin{array}{l}33 \\
8\end{array}$ & $\begin{array}{l}(12.1) \\
(5.8)\end{array}$ & $0.04 I$ & $\begin{array}{l}580 \\
280 \\
43\end{array}$ & $\begin{array}{l}(82.7) \\
(81.9) \\
(78.2)\end{array}$ & $\begin{array}{l}121 \\
62 \\
12\end{array}$ & $\begin{array}{l}(17.3) \\
(18.1) \\
(21.8)\end{array}$ & 0.729 \\
\hline
\end{tabular}

(Continued) 
Table 2 (Continued).

\begin{tabular}{|c|c|c|c|c|c|c|c|c|c|c|}
\hline & \multicolumn{5}{|c|}{ GDPH Group } & \multicolumn{5}{|c|}{ TCGA Group } \\
\hline & \multicolumn{2}{|c|}{ WT AKT } & \multicolumn{2}{|c|}{ MT AKT } & & \multicolumn{2}{|c|}{ WT AKT } & \multicolumn{2}{|c|}{ MT AKT } & \\
\hline & \multicolumn{2}{|c|}{$n=370$} & \multicolumn{2}{|c|}{$n=41$} & & \multicolumn{2}{|c|}{$n=903$} & \multicolumn{2}{|c|}{$n=195$} & \\
\hline & \multicolumn{2}{|c|}{$n(\%)$} & \multicolumn{2}{|c|}{$n(\%)$} & $\mathbf{P}$ & \multicolumn{2}{|c|}{$n(\%)$} & \multicolumn{2}{|c|}{$n(\%)$} & $\boldsymbol{P}$ \\
\hline $\begin{array}{l}\text { Hormone receptor status } \\
\text { Positive } \\
\text { Negative } \\
\text { NA }\end{array}$ & $\begin{array}{l}275 \\
95\end{array}$ & $\begin{array}{l}(89.0) \\
(93.1)\end{array}$ & $\begin{array}{l}34 \\
7\end{array}$ & $\begin{array}{l}(11.0) \\
(6.9)\end{array}$ & 0.226 & $\begin{array}{l}677 \\
185 \\
41\end{array}$ & $\begin{array}{l}(82.0) \\
(83.3) \\
(82.0)\end{array}$ & $\begin{array}{l}149 \\
37 \\
9\end{array}$ & $\begin{array}{l}(18.0) \\
(16.7) \\
(18.0)\end{array}$ & 0.635 \\
\hline $\begin{array}{l}\text { HER2 status } \\
\text { Positive } \\
\text { Negative } \\
\text { NA }\end{array}$ & $\begin{array}{l}116 \\
254\end{array}$ & $\begin{array}{l}(95.9) \\
(87.6)\end{array}$ & $\begin{array}{l}5 \\
36\end{array}$ & $\begin{array}{l}(4.1) \\
(12.4)\end{array}$ & 0.011 & $\begin{array}{l}165 \\
622 \\
116\end{array}$ & $\begin{array}{l}(84.2) \\
(81.8) \\
(81.7)\end{array}$ & $\begin{array}{l}31 \\
138 \\
26\end{array}$ & $\begin{array}{l}(I 5.8) \\
(I 8.2) \\
(I 8.3)\end{array}$ & 0.444 \\
\hline $\begin{array}{l}\text { Ki67 index } \\
\quad \geq 14 \% \\
\quad<14 \%\end{array}$ & $\begin{array}{l}40 \\
330\end{array}$ & $\begin{array}{l}(90.9) \\
(89.9)\end{array}$ & $\begin{array}{l}4 \\
37\end{array}$ & $\begin{array}{l}(9.1) \\
(10.1)\end{array}$ & 0.836 & NA & & & & NA \\
\hline $\begin{array}{l}\text { HR/HER2 status } \\
\text { HR-/HER2- } \\
\text { HR-/HER2+ } \\
\text { HR+/HER2- } \\
\text { HR+/HER2+ } \\
\text { NA }\end{array}$ & $\begin{array}{l}50 \\
45 \\
204 \\
71\end{array}$ & $\begin{array}{l}(94.3) \\
(91.8) \\
(86.1) \\
(98.6)\end{array}$ & $\begin{array}{l}3 \\
4 \\
33 \\
1\end{array}$ & $\begin{array}{l}(5.7) \\
(8.2) \\
(13.9) \\
(1.4)\end{array}$ & 0.010 & $\begin{array}{l}132 \\
35 \\
490 \\
130 \\
116\end{array}$ & $\begin{array}{l}(82.5) \\
(85.4) \\
(81.8) \\
(83.9) \\
(81.1)\end{array}$ & $\begin{array}{l}28 \\
6 \\
109 \\
25 \\
27\end{array}$ & $\begin{array}{l}(17.5) \\
(14.6) \\
(18.2) \\
(16.1) \\
(18.9)\end{array}$ & 0.890 \\
\hline
\end{tabular}

Abbreviations: GDPH, Guangdong Provincial People's Hospital; TCGA, The Cancer Genome Atlas; NA, not applicable; IDC, invasive ductal carcinoma; ILC, invasive lobular carcinoma; ER, estrogen receptor; PR, progesterone receptor; HER2, human epidermal growth factor receptor 2.

Clinical trial NCT01226316 showed that AZD5363 treatment led to a longer PFS in AKT1 E17K-mutant patients compared with patients without AKT1 E17K mutation. ${ }^{36}$ The effect of AKT inhibitors on the GDPH patients needs further investigation.

HER2 is a receptor tyrosine kinase that is geneamplified in about $20-25 \%$ of patients with breast cancer. Overexpression of HER2 is associated with tumor aggressiveness, while causing recurrent disease progression or shorter overall survival as well as resistance of patients to therapies. ${ }^{37,38}$ Previous studies have shown that HER2 and PR expression is correlated with AKT variation status. ${ }^{39}$ In the present study, we observed a strong inverse correlation between AKT variation and HER2 expression $(P=0.011)$, and a positive correlation between AKT variation and PR expression, while there was no significant correlation between AKT variation and ER expression. These results are inconsistent with the current data. This inconsistency could be attributed to the differences in AKT variation between the Chinese and European populations. As a result, more studies need to be conducted for understanding HER2 expression and AKT activity in different populations.

In this study, we identified significant differences in AKT variation between the Chinese and TCGA populations. For instances, breast cancer patients in the GDPH cohort had a higher rate of AKT1 mutation, but a lower rate of AKT3 mutation in comparison with those in the TCGA cohort; AKT variation was inversely correlated with HER2 expression, while being positively correlated with PR expression. Despite these observations, the limited sample size in the study may decrease the statistical ability to make accurate comparisons between the two cohorts. In addition, this study did not explore the correlation between AKT variations and the prognosis of breast cancer patients, which is the limitation of this project. Previous studies have shown that the AKT1-E17K 
Table 3 AKT Inhibitors in Clinical Development

\begin{tabular}{|c|c|c|}
\hline Drug & Phase & Clinical Trials \\
\hline Perifosine & $\mathrm{II} / \mathrm{III}$ & $\begin{array}{l}\text { NCTOI05I557 NCT0I04984I } \\
\text { NCT0I0970I8 NCTOI } 224730 \\
\text { NCT02238496 }\end{array}$ \\
\hline MK-2206 & II & $\begin{array}{l}\text { NCT0I } 802320 \text { NCT0I } 776008 \\
\text { NCT0I } 859182 \text { NCT0I783I I I } \\
\text { NCT0I } 705340\end{array}$ \\
\hline $\begin{array}{l}\text { Uprosertib } \\
\text { (GSK214I795) }\end{array}$ & II & $\begin{array}{l}\text { NCTOI94I927 NCTO19078I5 } \\
\text { NCT01935973 }\end{array}$ \\
\hline $\begin{array}{l}\text { Afuresertib } \\
\text { (GSK2110183) }\end{array}$ & $\mathrm{I} / \mathrm{II}$ & $\begin{array}{l}\text { NCT023803 I } 3 \text { NCT02235740 } \\
\text { NCT022402 I } 2 \text { NCT02 I77682 } \\
\text { NCT02040480 }\end{array}$ \\
\hline $\begin{array}{l}\text { Ipatasertib (GDC- } \\
\text { 0068, RG7440) }\end{array}$ & $\mathrm{I} / \mathrm{II}$ & $\begin{array}{l}\text { NCTOI } 896530 \text { NCTOI } 48586 I \\
\text { NCT0I } 362374 \text { NCT0I090960 }\end{array}$ \\
\hline AZD5363 & II & $\begin{array}{l}\text { NCT02576444 NCT02664935 } \\
\text { NCT02449655 NCT0245I956 } \\
\text { NCT02525068 }\end{array}$ \\
\hline ARQ0092 & I & $\begin{array}{l}\text { NCT02476955 NCT0I473095 } \\
\text { NCT025942II }\end{array}$ \\
\hline ATI3।48 & I & NCT0I58570I \\
\hline GSK690963 & Failed & \\
\hline XLI48 & Failed & \\
\hline
\end{tabular}

mutation does not seem to have obvious prognostic significance in breast cancer patients, but it has clinical utility in the selection of therapeutic drugs. Given that plenty of studies suggest AKT to be a well-approved target for medicines development, further investigation of mechanisms underlying AKT and its inhibitors in breast cancer could provide a theoretical basis for clinical application of AKT as an effective therapeutic target.

\section{Funding}

This work was supported by funds from High-level Hospital Construction Project (DFJH201921, Bo Chen); the National Natural Science Foundation of China (81902828, Bo Chen; 82002928, Jianguo Lai); Natural Science Foundation of Guangdong Province (2016A030313768, Ning Liao; 2018A030313292) and Research Funds from Guangzhou Municipal Science and Technology Project (201707010418, Ning Liao); the Fundamental Research Funds for the Central Universities (y2syD2192230, Bo Chen); Medical Scientific Research Foundation of Guangdong Province (B2019039, Bo Chen); the Doctor Launch Fund of Guangdong Provincial
People's hospital (2018bq02,Bo Chen; 2020bq11, Jianguo Lai) and Research Funds from Guangzhou Municipal Science and Technology Project (grant numbers: 201707010418; 201804010430). The funding bodies have no role in the design of the study, the collection, analysis, and interpretation of data and in writing the manuscript.

\section{Disclosure}

The authors declare that they have no conflicts of interest in this work.

\section{References}

1. Ferlay J, Soerjomataram I, Dikshit R, et al. Cancer incidence and mortality worldwide: sources, methods and major patterns in GLOBOCAN 2012. Int J Cancer. 2015;136(5):E359-E386. doi:10.1002/ijc.29210

2. Ginsburg O, Bray F, Coleman MP, et al. The global burden of women's cancers: a grand challenge in global health. Lancet. 2017;389:847-860. doi:10.1016/S0140-6736(16)31392-7

3. Rui-Mei, Feng, Yi-Nan, et al. Current cancer situation in China: good or bad news from the 2018 Global Cancer Statistics? Cancer Commun. 2019;39:22-34. doi:10.1186/s40880-019-0368-6

4. Garraway LA. Genomics-driven oncology: framework for an emerging paradigm. J Clin Oncol. 2013;31:1806-1814. doi:10.1200/ JCO.2012.46.8934

5. Nicholson KM, Anderson NG. The protein kinase B/Akt signalling pathway in human malignancy. Cell Signal. 2002;14:381-395. doi:10.1016/s0898-6568(01)00271-6

6. Bozhanov SS, Angelova SG, Krasteva ME, et al. Alterations in p53, BRCA1, ATM, PIK3CA, and HER2 genes and their effect in modifying clinicopathological characteristics and overall survival of Bulgarian patients with breast cancer. $J$ Cancer Res Clin Oncol. 2010;136:1657-1669. doi:10.1007/s00432-010-0824-9

7. Chu N, Viennet T, Bae H, et al. The structural determinants of $\mathrm{PH}$ domain-mediated regulation of Akt revealed by segmental labeling. eLife. 2020:9. doi:10.7554/eLife.59151

8. Grille S, Bellacosa A, Upson J, et al. The protein kinase Akt induces epithelial mesenchymal transition and promotes enhanced motility and invasiveness of squamous cell carcinoma lines. Cancer Res. 2003;63:2172-2178.

9. Tokunaga E, Kimura Y, Oki E, et al. Akt is frequently activated in HER2/neu-positive breast cancers and associated with poor prognosis among hormone-treated patients. Int J Cancer. 2010;118:284-289. doi:10.1002/ijc. 21358

10. Network TCGA. Comprehensive molecular portraits of human breast tumors. Nature. 2012;490:61-70. doi:10.1038/nature11412

11. Futreal PA, Chin L, Andersen JN. Cancer genomics: from discovery science to personalized medicine. Nat Med. 2011;17:297-303. doi: $10.1038 / \mathrm{nm} .2323$

12. Blum A, Wang P, Zenklusen JC. SnapShot: TCGA-analyzed tumors. Cell. 2018;173:530. doi:10.1016/j.cell.2018.03.059

13. Spratt DE, Chan T, Waldron L, et al. Racial/ethnic disparities in genomic sequencing. JAMA Oncol. 2016;2:1070-1074. doi:10.1001/ jamaoncol.2016.1854

14. López-Knowles E, O’Toole S, McNeil C, et al. PI3K pathway activation in breast cancer is associated with the basal-like phenotype and cancer-specific mortality. Int $J$ Cancer. 2010;126:1121-1131. doi:10.1002/ijc. 24831

15. Araki K, Miyoshi Y. Mechanism of resistance to endocrine therapy in breast cancer: the important role of PI3K/Akt/mTOR in estrogen receptor-positive, HER2-negative breast cancer. Breast Cancer. 2018;25:392-401. doi:10.1007/s12282-017-0812-x 
16. Wolff A, Hammond M, Allison K, et al. Human epidermal growth factor Receptor 2 testing in breast cancer: american Society of Clinical Oncology/College of American pathologists clinical practice guideline focused update. J Clin Oncol. 2018;36:2105-2122. doi:10.1200/jco.2018.77.8738

17. Zhang X, Liang Z, Wang S, et al. Application of next-generation sequencing technology to precision medicine in cancer: joint consensus of the Tumor Biomarker Committee of the Chinese Society of Clinical Oncology. Cancer Biol Med. 2019;16:189-204. doi:10.20892/j.issn.2095-3941.2018.0142

18. Mao X, Zhang Z, Zheng X, et al. Capture-based targeted ultradeep sequencing in paired tissue and plasma samples demonstrates differential subclonal ctDNA-releasing capability in advanced lung cancer. J Thorac Oncol. 2017;12:663-672. doi:10.1016/j.jtho.2016.11.2235

19. Li YS, Jiang BY, Yang JJ, et al. Unique genetic profiles from cerebrospinal fluid cell-free DNA in leptomeningeal metastases of EGFR-mutant non-small-cell lung cancer: a new medium of liquid biopsy. Ann Oncol. 2018;29:945-952. doi:10.1093/annonc/mdy009

20. Xie Z, Liu L, Lin X, Xie X, Qin Y. A multicenter analysis of genomic profiles and PD-L1 expression of primary lymphoepithelioma-like carcinoma of the lung. Modern Pathol. 2019;33:626-638. doi:10.1038/s41379-019-0391-9

21. Askham JM, Platt F, Chambers PA, Snowden H, Taylor CF, Knowles MA. AKT1 mutations in bladder cancer: identification of a novel oncogenic mutation that can co-operate with E17K. Oncogene. 2010;29:150-155. doi:10.1038/onc.2009.315

22. Carpten J, Faber A, Horn C, et al. A transforming mutation in the pleckstrin homology domain of AKT1 in cancer. Nature. 2007;448:439-444. doi:10.1038/nature05933

23. Downward J. Targeting RAS signalling pathways in cancer therapy. Nat Rev Cancer. 2003;3:11-22. doi:10.1038/nrc969

24. Tamura K, Hashimoto J, Tanabe Y, et al. Safety and tolerability of AZD5363 in Japanese patients with advanced solid tumors. Cancer Chemother Pharmacol. 2016;77:1-9. doi:10.1007/s00280-016-2987-9

25. Nitulescu GM, Margina D, Juzenas P, Peng Q, Tsatsakis AM. Akt inhibitors in cancer treatment: the long journey from drug discovery to clinical use (Review). Int J Oncol. 2016;48:869-885. doi:10.3892/ ijo.2015.3306

26. Banerji U, Dean E, Pérez-Fidalgo J, et al. PIK3CAA Phase I open-label study to identify a dosing regimen of the Pan-AKT inhibitor AZD5363 for evaluation in solid tumors and in -mutated breast and gynecologic cancers. Clin Cancer Res. 2018;24:2050-2059. doi:10.1158/1078-0432.ccr-17-2260

27. Dean E, Banerji U, Schellens JHM, et al. A Phase 1, open-label, multicentre study to compare the capsule and tablet formulations of AZD5363 and explore the effect of food on the pharmacokinetic exposure, safety and tolerability of AZD5363 in patients with advanced solid malignancies: OAK. Cancer Chemother Pharmacol. 2018;81:873-883. doi:10.1007/s00280-018-3558-z
28. Schmid P, Wheatley D, Baird R, et al. Abstract OT1-03-13: a Phase II, double blind, randomised, placebo-controlled study of the AKT Inhibitor AZD5363 in combination with paclitaxel in triple-negative advanced or metastatic breast cancer (TNBC)(NCT02423603). Cancer Res. 2016;76:OT1-03-13-OT01-03-13.

29. Rinnerthaler G, Gampenrieder SP, Greil R. ASCO 2018 highlights: metastatic breast cancer. Magazine Eur Med Oncol. 2018;11:276-279. doi:10.1007/s12254-018-0450-9

30. Wu W, Chen Y, Huang L, Li W, Tao C, Shen H. Effects of AKT1 E17K mutation hotspots on the biological behavior of breast cancer cells. Int J Clin Exp Pathol. 2020;13:332-346.

31. Cizkova M, Vacher S, Meseure D, Trassard M, Bièche I. PIK3R1 underexpression is an independent prognostic marker in breast cancer. BMC Cancer. 2013;13:545. doi:10.1186/1471-2407-13-545

32. Stemke-Hale K, Gonzalez-Angulo AM, Lluch A, et al. An integrative genomic and proteomic analysis of PIK3CA, PTEN, and AKT mutations in breast cancer. Cancer Res. 2008;68:6084-6091. doi:10.1158/ 0008-5472.CAN-07-6854

33. Jansen VM, Mayer IA, Arteaga CL. Is there a future for AKT inhibitors in the treatment of cancer? Clin Cancer Res. 2016;22:2599-2601. doi:10.1158/1078-0432.CCR-16-0100

34. Landgraf K, Pilling C, Falke J. Molecular mechanism of an oncogenic mutation that alters membrane targeting: glu17Lys modifies the PIP lipid specificity of the AKT1 PH domain. Biochemistry. 2008;47:12260-12269. doi:10.1021/bi801683k

35. Kumar A, Purohit R. Cancer associated E17K mutation causes rapid conformational drift in AKT1 pleckstrin homology (PH) domain. PLoS One. 2013;8:e64364. doi:10.1371/journal.pone.0064364

36. Hyman DM, Smyth LM, Donoghue MTA, Westin SN, Taylor BS AKT inhibition in solid tumors with AKT1 mutations. J Clin Oncol. 2017;35:2251-2259. doi:10.1200/JCO.2017.73.0143

37. Slamon D, Clark G, Wong S, Levin W, Ullrich A, Mcguire W. Human breast cancer: correlation of relapse and survival with amplification of the HER-2/neu oncogene. Science. 1987;235:177-182. doi:10.1126/science. 3798106

38. Alaoui-Jamali MA, Paterson J, Moustafa AEA, Yen L. The role of ErbB-2 tyrosine kinase receptor in cellular intrinsic chemoresistance: mechanisms and implications. Biochem Cell Biol/Biochimie Et Biologie Cellulaire. 1997;75:315-325. doi:10.1139/097-060

39. Cui X, Zhang P, Deng W, et al. Insulin-like growth factor-I inhibits progesterone receptor expression in breast cancer cells via the phosphatidylinositol 3-kinase/Akt/mammalian target of rapamycin pathway: progesterone receptor as a potential indicator of growth factor activity in breast cancer. Mol Endocrinol. 2003;17:575-588. doi: $10.1210 /$ me.2002-0318

\section{Publish your work in this journal}

Cancer Management and Research is an international, peer-reviewed open access journal focusing on cancer research and the optimal use of preventative and integrated treatment interventions to achieve improved outcomes, enhanced survival and quality of life for the cancer patient.
The manuscript management system is completely online and includes a very quick and fair peer-review system, which is all easy to use. Visit http://www.dovepress.com/testimonials.php to read real quotes from published authors. 